\title{
A multi-input energy harvesting system with independent energy harvesting block and power management block
}

\author{
Eun Jeong Yun ${ }^{1}$, Hyeon Joong Kim², Chong Gun $\mathrm{Yu}^{3}$ \\ ${ }^{1}$ Institute GMC Team, MS Development, Silicon Works Co. LTD, Seoul, Republic of Korea \\ ${ }^{2,3}$ Department of Electronics Engineering, Incheon National University, Incheon, Republic of Korea
}

\begin{tabular}{l} 
Article Info \\
\hline Article history: \\
Received Jul 21, 2021 \\
Revised Sep 24, 2021 \\
Accepted Oct 6, 2021 \\
\hline Keywords: \\
Energy harvesting \\
Maximum power point tracking \\
Photovoltaic energy \\
Piezoelectric energy \\
Thermoelectric energy
\end{tabular}

Article Info

Article history

Received Jul 21, 2021

Revised Sep 24, 2021

Accepted Oct 6, 2021

\section{Keywords:}

Energy harvesting

Photovoltaic energy

Thermoelectric energy

\begin{abstract}
In the conventional approach widely used for multi-input energy harvesting (MIEH), energy harvesting, energy combining, and power conversion are performed integrally in an inductor sharing block through time multiplexing operations, which is not suitable for hot-pluggable systems. In the MIEH system proposed in this paper, an energy harvesting block (EHB) and a power management block (PMB) are independent of each other to increase the modularity of the system. Therefore, the EHB can be optimized to extract maximum power from energy sources, and the PMB can be focused on combining input energies and converting power effectively. This paper mainly focuses on the design and implementation of the EHB. For light, vibration, and thermal energy, the measured peak power efficiencies of the EHB implemented using a $0.35 \mu \mathrm{m}$ CMOS process are $95.2 \%, 92.5 \%$, and $95.5 \%$, respectively. To confirm the functionality and effectiveness of the proposed MIEH system, a PMB composed of simple charge pump circuits and a power management unit has also been implemented and verified with the designed EHB.
\end{abstract}

This is an open access article under the CC BY-SA license.

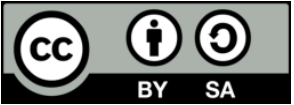

\section{Corresponding Author:}

Chong Gun $\mathrm{Yu}$

Department of Electronics Engineering

Incheon National University

119 Academy-ro, Yeonsu-gu, Incheon, Republic of Korea

Email: chong@inu.ac.kr

\section{INTRODUCTION}

Recently, harvesting ambient energy to power small-sized electronic devices has attracted considerable research interest. To achieve self-powering without batteries and near-permanent operation, energy harvesting is already essential for the development of low-power and small-sized sensing systems such as wireless sensor nodes [1]-[6] and wearable/implantable devices [7]-[9]. Several environmental energy sources such as light, vibration, thermal, and radio frequency (RF) energy are utilized for energy harvesting. These energies are typically converted into electrical energy using energy transducers such as photovoltaic (PV) cells, piezoelectric (PE) transducers, thermoelectric (TE) generators, and rectifying antennas. However, the power obtainable from a single energy source is limited to a few microwatts or less for many applications [7]. Since energy transducers used in small electronic systems are limited in size, the energy harvested is further limited. Also, the energy sources can be unstable. Thus, single-input energy harvesting (SIEH) systems have limited application areas because they can only operate in limited operating modes such as burst mode or active/sleep mode [10], [11]. In this mode of operation, the system activates when there is enough energy and goes into sleep mode when there is insufficient energy available. Therefore, harvesting energy from multiple available sources is desirable to increase the overall system reliability and is currently considered a promising way to improve energy harvesting capabilities [12]-[29]. 
Multi-input energy harvesting (MIEH) can be classified into homogeneous MIEH (HO-MIEH) and heterogeneous MIEH (HE-MIEH) depending on the type of energy sources used. HO-MIEH utilizes multiple energy sources of the same type such as PV cells (PVCs) [12], [13], PE transducers (PZTs) [14]-[16], and TE generators (TEGs) [17], [24]. Obviously, HO-MIEH is more advantageous for increasing the overall input power than SIEH. HO-MIEH is also useful for improving the dynamic range of an energy harvesting system. For example, multiple differently sized PZTs can be used to utilize broadband vibration [15] or various types of human movement [16]. However, the HO-MIEH system may not be suitable for maintaining system operation because ambient energy sources are often irregular or intermittent depending on environmental conditions. For example, outdoor light energy can be used only in the daytime. Thus, harvesting energy from various types of energy sources, as in $\mathrm{HE}-\mathrm{MIEH}$, is more appropriate for improving the system sustainability, in such a way that the system does not rely solely on energy sources of the same type. As an example, HEMIEH is the best approach for wearable electronics applications [7]-[9], where energy can be harvested from multi-type sources such as body heat and movements, ambient light, and RF energy from hand-held devices.

A typical block diagram of SIEH systems is shown in Figure 1. The first part of the system, the energy harvester, consists of a transducer that converts certain types of ambient energy into electrical energy and an interface circuit that performs certain operations, such as maximum power point tracking (MPPT), to extract the maximum available power from the energy source. The power management unit (PMU), the second part of the system, conditions the power flow from the energy harvester to the output load. It usually consists of DC-DC converters and associated circuitry to charge an energy storage device (ESD) (e.g., a super-capacitor or a rechargeable battery) or to power the output load. To improve the system efficiency, the PMU and interface circuitry should perform their given roles with very low power consumption. In MIEH systems, there is another specific issue, which is energy combining. Combining energy from multiple sources should be performed simultaneously and efficiently to minimize energy losses when merging the energies of individual harvesters. MIEH systems can be classified into two types according to the order of energy combining and power conversion as shown in Figure 2.

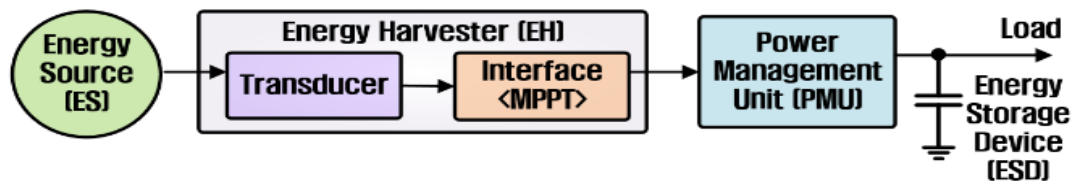

Figure 1. Block diagram of a typical SIEH system

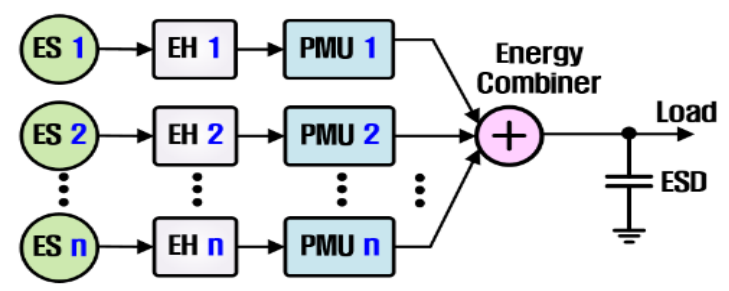

(a)

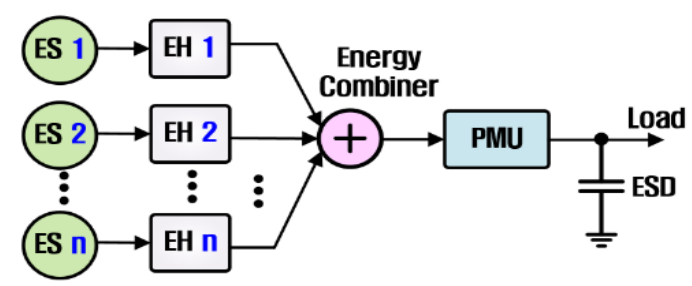

(b)

Figure 2. Energy combining method in MIEH system: (a) basic method and (b) more efficient method

A straightforward method [18] for energy combining in a MIEH system is to merge the energy output from each SIEH system as shown in Figure 2(a), where power conversion for each energy source is performed first, followed by energy combining. The advantage of this approach is that the PMU can be optimized independently for each energy source. However, when more energy sources are combined, the number of PMUs increases, requiring more components, resulting in larger volume sizes, higher power losses, and higher costs. A more efficient method [19]-[26] for energy combining is to merge the energy from each energy harvester first and then perform power conversion on the merged energy as shown in Figure 2(b). This approach uses only one PMU, thereby reducing system form factor, power loss, and cost. Therefore, most micro energy harvesting systems adopt this approach. Table 1 summarizes the properties of recent MIEH systems using this approach.

Recently, a variety of energy combining techniques have been reported such as power ORing using diodes [20], [21], selecting a harvester generating maximum instantaneous power [30], summing the output 
voltages from individual harvesters by stacking each storage capacitor [31], and sharing a single inductor for power conversion [22]-[26]. The last of these methods has been the preferred and widely used approach because it can harvest energy from all energy sources without large energy loss and has relatively high system efficiency. In this approach, interface (MPPT), energy combining, and power conversion are generally performed integrally in the inductor sharing block, switched-inductor circuitry, as shown in Figure 3 . In the inductor sharing block, a time-multiplexed operation is usually used for energy combining and for sharing of the power stage between different input sources, resulting in a reduced number of components. However, complex timing control is required to drive switches required for time-multiplexed operation, and controller modification is inevitable to change the number of energy sources. This is because, when an energy source is added, a new time interval must be allocated for energy harvesting from the added energy source, and if the energy source is removed, energy is not harvested during the time period allocated to the removed energy source. Therefore, this approach is not suitable for a hot-pluggable system in which addition or removal of an energy source can be performed independently.

Table 1. Performance comparison of recent multi-input energy harvesting system

\begin{tabular}{|c|c|c|c|c|c|}
\hline & [19] & {$[24]$} & {$[25]$} & {$[26]$} & This work \\
\hline No. of inputs & 3 & 9 & 3 & 2 & 3 \\
\hline Type of sources & $\begin{array}{l}\text { Light, Vibration } \\
\text { RF }\end{array}$ & $\begin{array}{l}\text { Light, Vibration } \\
\text { Thermal }\end{array}$ & $\begin{array}{l}\text { Light, Thermal } \\
\text { Biofuel }\end{array}$ & Vibration, Thermal & $\begin{array}{l}\text { Light, Vibration } \\
\text { Thermal }\end{array}$ \\
\hline $\begin{array}{l}\text { Energy combine } \\
\text { technique }\end{array}$ & $\begin{array}{l}\text { Parallel-connected } \\
\text { LDOs }\end{array}$ & $\begin{array}{l}\text { Inductor sharing } \\
\text { (PBQ) }\end{array}$ & $\begin{array}{l}\text { Inductor sharing } \\
\text { (time-mx) }\end{array}$ & $\begin{array}{l}\text { Inductor sharing } \\
\text { (time-mx) }\end{array}$ & Charge pump \\
\hline Power conversion & Band-band control & Buck-boost & Buck-boost & Boost & Band-band control \\
\hline Energy storage & Capacitor & Capacitor & Battery & Capacitor, Battery & Capacitor \\
\hline $\begin{array}{l}\text { Peak } \\
\text { Efficiency }(\%)\end{array}$ & N.A. & $\begin{array}{l}89.6(\mathrm{PE}), \\
81.0(\mathrm{HV}) \\
63.8(\mathrm{LV})\end{array}$ & 89 & 82 & $\begin{array}{l}95.2 \text { (PVEI) } \\
92.5 \text { (PEEI) } \\
95.5 \text { (TEEI) }\end{array}$ \\
\hline Output voltage (V) & $1 \sim 1.2$ & $<5 \mathrm{~V}$ & $0.4 \sim 1.4$ & $1.2 \sim 1.8$ & $1.8 \sim 2.0$ \\
\hline Power /current & $220 \mu \mathrm{W}$ & $431 n A$ & $262 n A$ & $582 \mathrm{nW}$ & $19 \mu \mathrm{W}$ \\
\hline
\end{tabular}

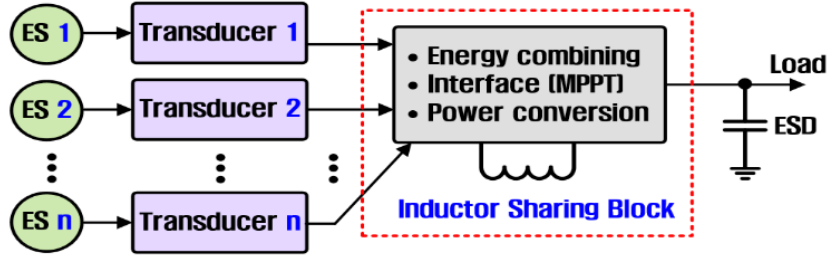

Figure 3. Block diagram of a MIEH system using an inductor sharing block

For power conversion in the inductor sharing approach, mainly boost [22], [23], [26] or buckboost [24], [25] type DC-DC converters are used. Sometimes, two types of converters (e.g., boost and buckboost [22], boost and buck [23]) may be used together to provide a regulated voltage to the load. For the interface to achieve maximum power extraction in such a single-inductor architecture, an impedance matching technique is usually utilized as a simple and low-power MPPT method. In this scheme, the input impedance of the power converter is adjusted to match the internal impedance of the energy transducers by controlling the effective switching frequency [22], [25], [26] or duty cycle [23], [25], [26] of the power converter. For a simple MPPT implementation, a one-time setting during installation is performed to set the switching frequency or duty cycle, assuming that the transducer's internal impedance is known in advance. However, the internal impedance of a transducer can change with environmental conditions. For example, the TEG's internal impedance varies with temperature differences and can deviate by $12 \%$ from its nominal 
value [32]. Also, typical inductor has an inductance tolerance of at least $\pm 20 \%$. In addition, the frequency generated by on-chip clock oscillators is highly dependent on process, voltage, temperature (PVT) changes. Therefore, this one-time setting method is difficult to effectively track the maximum power point (MPP).

In this paper, we propose a MIEH system in which the energy harvester block (EHB) and the PMU block (PMB) are independent of each other to increase the modularity of the system. In the proposed system, as shown in Figure 4, the EHB and PMB share the required work for the entire system and independently perform the work given to each. Thus, the EHB can be optimized to extract maximum available power from energy sources, and the PMB can be focused on the function of efficiently merging input energies and converting power regardless of the number of active energy sources. In addition, since the two blocks are independent, it is possible to add or remove energy sources without modifying the PMB. This paper mainly focuses on the design and verification of the EHB using light, vibration, and thermal energy. MPPT, the main function of the EHB, is implemented using the fractional open-circuit voltage (FOCV) method [33], which is simple but can achieve relatively high accuracy. The FOCV method is based on the observation that the MPP voltage of an energy transducer is linearly proportional to its open-circuit voltage. To confirm the functionality of the proposed MIEH system, a PMB composed of simple charge pump (CP) circuits and a PMU with a band-band control (BBC) function has been implemented and verified with the EHB. As a more efficient PMB, the buck-boost converter using the priority-based queuing technique proposed in [24] is one of the optimal candidates. In section 2 characteristics of the energy transducers used in this paper are described. The overall architecture of the designed system and the implementation of its component blocks are described in section 3 . Section 4 presents the obtained experimental results, and section 5 concludes the paper.

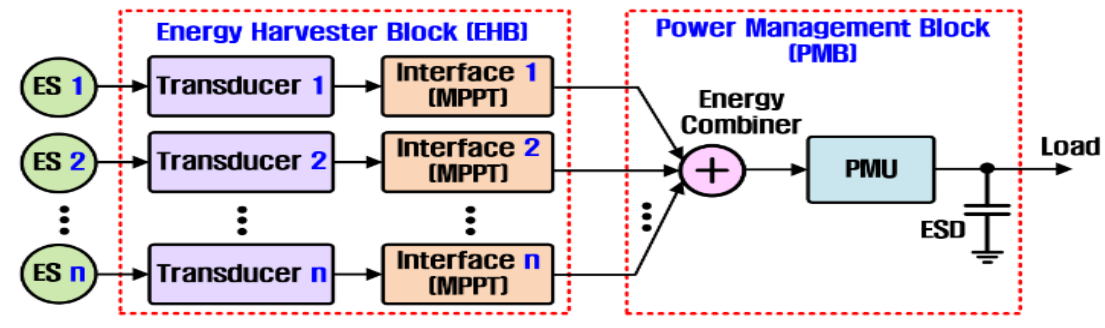

Figure 4. Proposed MIEH system architecture

\section{CHARACTERISTICS OF ENERGY TRANSDUCERS}

\subsection{Photovoltaic cell (PVC)}

The MPP voltage of an energy transducer is a fraction of its open-circuit voltage $\left(V_{\mathrm{OC}}\right)$, and the relationship can be expressed as $V_{\mathrm{MPP}}=K_{\mathrm{MPP}} V_{\mathrm{OC}}$. The $K_{\mathrm{MPP}}$ for PVCs usually ranges from 0.65 to 0.8 , which depends on the specific PV module being used and also depends on light intensity [33]-[35]. The PVC used in this paper for harvesting light energy is a Solarbotics solar cell (SCC2422) [36]. Figure 5(a) is the equivalent circuit [33] of the PVC used in circuit simulation, and Figure 5(b) is the I-V and P-V characteristic graph of the PVC. Measurement results show that the PVC exhibits an open-circuit voltage $\left(V_{\mathrm{PVC}, \mathrm{OC}}\right)$ of about $3 \mathrm{~V}$, a maximum available power $\left(P_{\mathrm{PVC}, \mathrm{MAX}}=P_{\mathrm{PVC}, \mathrm{MPP}}\right)$ of $4.5 \mathrm{~mW}$, and a $K_{\mathrm{MPP}}$ of 0.7 at a light intensity of $40 \mathrm{klux}[35]$.

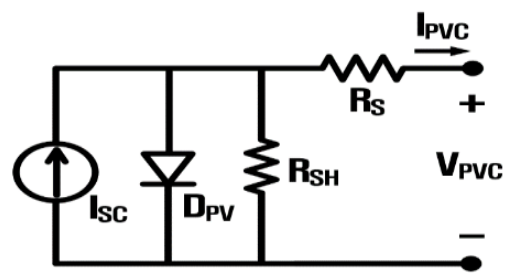

(a)

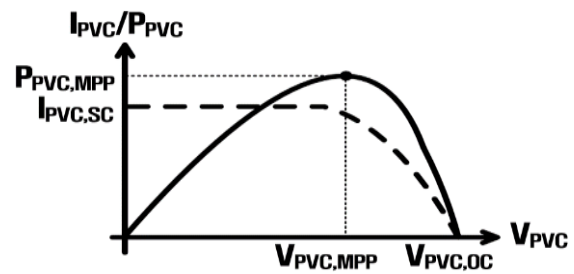

(b)

Figure 5. PVC: (a) equivalent circuit and (b) I-V and P-V characteristics

\subsection{Piezoelectric generator (PEG)}

Among the various methods used to convert vibration energy into electrical energy, PZTs utilizing the piezoelectric effect are mainly used [10]. A PZT can be modeled as an AC current source $I_{\mathrm{P}}$ and a parallel 
internal capacitor $C_{\mathrm{P}}$ as shown in Figure 6(a). The amplitude of the current source changes according to the frequency and magnitude of the vibration. The output of a PZT is a kind of AC signal, so an AC-DC converter (ADC) is needed to generate a DC signal. Figure 6(b) shows the I-V and P-V characteristics of a piezoelectric generator (PEG), a PZT connected to an ADC. The $K_{\mathrm{MPP}}$ for PEGs is 0.5 . The PZT used in this work is the Quick Pack QP20W [37]. The $C_{\mathrm{P}}$ value is $200 \mathrm{nF}$. The open-circuit voltage $\left(V_{\mathrm{PEG}, \mathrm{OC}}\right)$ is about $3 \mathrm{~V}$, and the maximum generated power $\left(P_{\mathrm{PEG}, \mathrm{MAX}}\right)$ is $125 \mu \mathrm{W}$ at a frequency of $80 \mathrm{~Hz}$ and vibration amplitude of $7 \mathrm{~m} / \mathrm{s}^{2}[10]$.

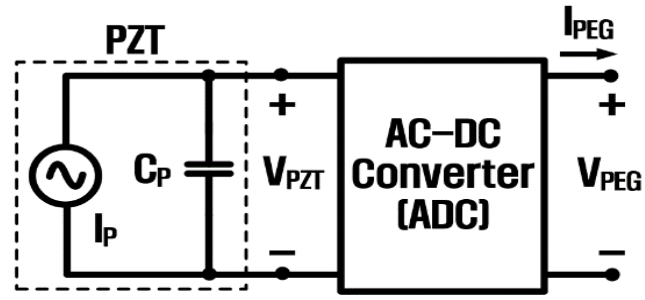

(a)

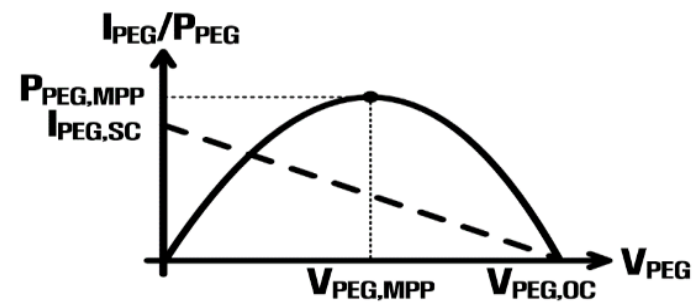

(b)

Figure 6. PEG: (a) architecture (a PZT connected to an ADC) and (b) I-V and P-V characteristics

\subsection{Thermoelectric generator (TEG)}

TEGs utilize the Seebeck effect of generating electromotive force when there is a temperature difference between the top and bottom of the thermoelectric device. A TEG can be modeled as a voltage source $V_{\mathrm{T}}$ connected in series with an internal resistor $R_{\mathrm{T}}$ as shown in Figure 7(a) [22]. Figure 7(b) is the I-V and P-V characteristic graph of the TEG. The $K_{\mathrm{MPP}}$ for TEGs is 0.5 . In this work, a $3-\mathrm{V}$ source with a $15-\mathrm{k} \Omega$ series resistor is used to emulate the TEG device presented in [38]. It is also equivalent to 17 commercial Thermo Life TEGs (Thermo Life ${ }^{\mathrm{TM}}$ ) [39] connected in parallel at a temperature difference of $3{ }^{\circ} \mathrm{C}$. The opencircuit voltage $\left(V_{\mathrm{TEG}, \mathrm{OC}}\right)$ is about $3 \mathrm{~V}$, and the maximum available power $\left(P_{\mathrm{TEG}, \mathrm{MAX}}\right)$ is $150 \mu \mathrm{W}$.

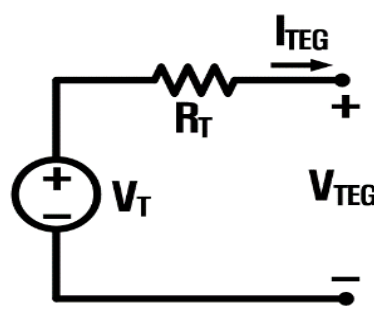

(a)

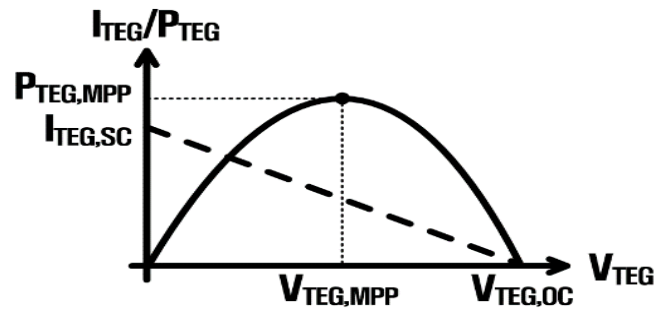

(b)

Figure 7. TEG: (a) equivalent circuit and (b) I-V and P-V characteristics

\section{DESIGN OF THE PROPOSED MIEH SYSTEM}

\subsection{Overall circuit description}

The architecture of the proposed HE-MIEH system is shown in Figure 8. Three types of energy sources are used in this design, but additional inputs can be connected in a hot-pluggable form, and the number of inputs can be easily expanded. The EHB consists of three interfaces: a PV energy interface (PVEI), a PE energy interface (PEEI), and a TE energy interface (TEEI). Each interface can be optimized independently of the PMB to extract maximum power from its energy source. In each interface channel, the maximum power is harvested from the energy source by an MPPT controller and delivered to the PMB. As mentioned in Section 1, in this prototype design, the energy harvested from each channel is combined into a storage capacitor $C_{\text {STO using }}$ simple CP circuits. The energy stored in $C_{\text {STO }}$ is then fed to the load through the PMU's BBC. The power harvested from small-sized energy transducers is usually not enough to drive load applications. To overcome this mismatch problem, the active/sleep technique is implemented using a simple BBC function [35]. 


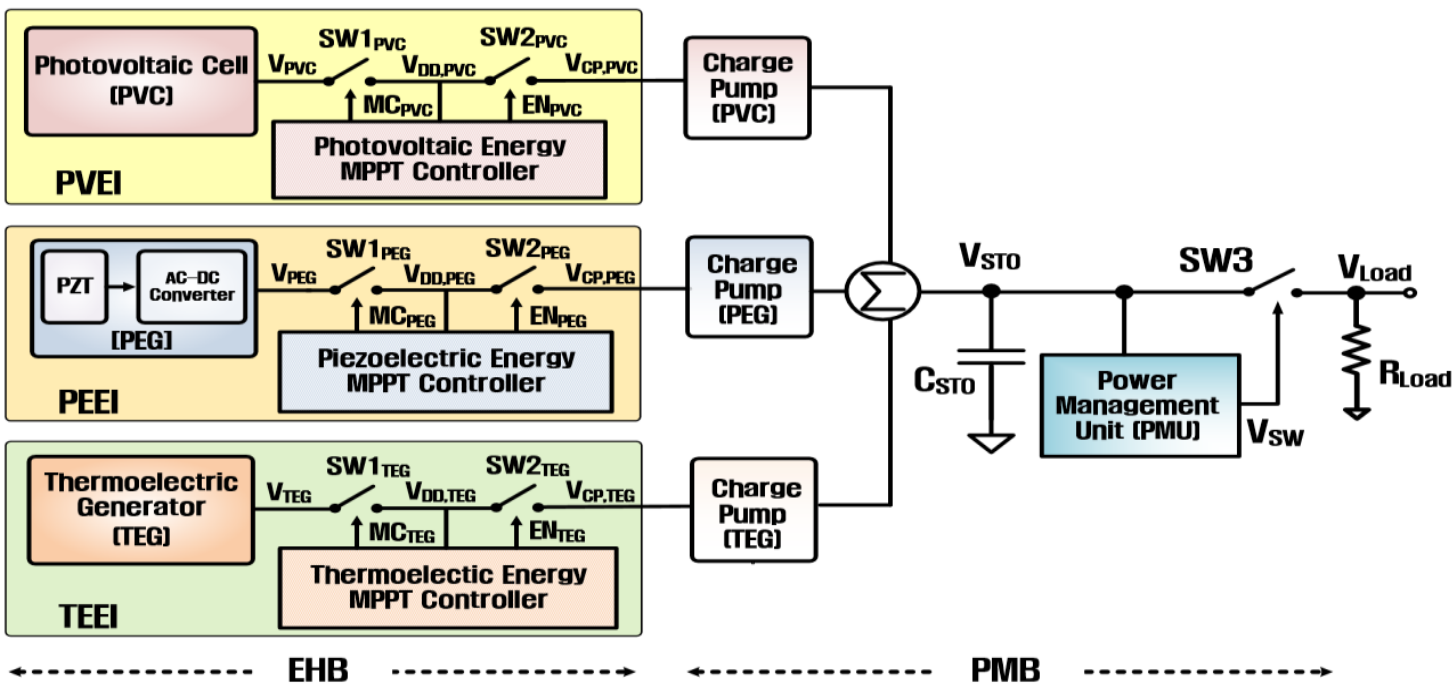

Figure 8. Architecture of the proposed multi-input energy harvesting system

\subsection{AC-DC converter (ADC)}

To transmit the maximum power from the vibration energy harvester to the load, the ADC in the PEEI should be designed with high conversion efficiency. In conventional passive ADCs using 4 diodeconnected MOSFETs [40] or gate cross-coupled ADCs using 2 MOSFET switches and 2 MOSFET diodes [10], the available output voltage is reduced due to the diode voltage drop, reducing overall efficiency. In this paper, the active ADC [41] shown in Figure 9 is employed for AC-DC conversion without diode voltage drop. The designed ADC consists of 2 NMOS switches and 2 active diodes, and the active diode is implemented as a comparator and a PMOS switch.

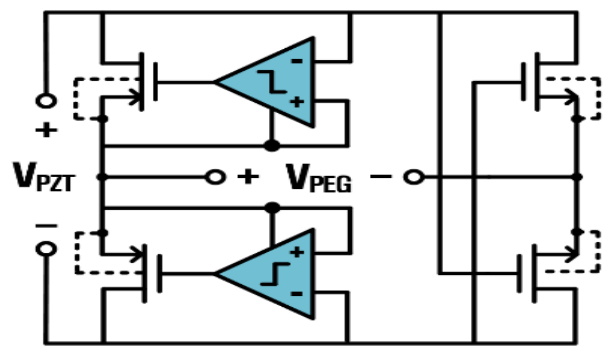

Figure 9. AC-DC converter for PEEI

\subsection{MPPT controller}

The MPPT controller for each interface channel is shown in Figure 10. The controller has been proposed in our previous work [42]. The pulse generator generates a pulse signal $M C$ for periodically opening the PMOS switch (SW1) to sample the open-circuit voltage $V_{\mathrm{OC}}$ of the energy transducer. While SW1 is closed, the energy harvested from the energy transducer is stored in $C_{\mathrm{DD}}$, and the voltage $V_{\mathrm{DD}}$ equals the output voltage of the energy transducer. For MPPT operation, load matching is performed by adaptively connecting the $V_{\mathrm{DD}}$ node to the output node $V_{\mathrm{CP}}$ by turning the PMOS switch (SW2) on or off. The enable generator compares $V_{\mathrm{DD}}$ with the MPP voltages generated by the sampler to generate the $E N$ signal, which is the control signal of SW2. In practice, a reference voltage that corresponds to $V_{\mathrm{MPP}} / n$ instead of $V_{\mathrm{MPP}}$ is generated for proper operation of internal circuits. In this design, the variable $n$ is set to 6 for light energy and 4 for vibration and thermal energy. The $K_{\mathrm{MPP}}$ is set to 0.7 for light energy and 0.5 for vibration and thermal energy. Details of the implementation of building blocks and the operation characteristics of the MPPT controller can be found in [42]. 


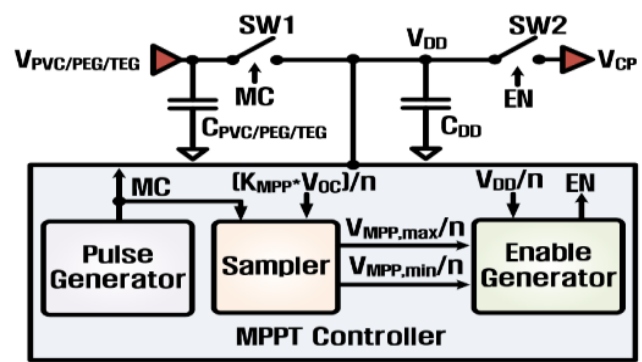

Figure 10. Proposed MPPT controller

The pulse generator consists of a clock generator and a 7-bit counter. The clock generator is a ringtype oscillator and generates a clock signal $C L K$ with a frequency of about $125 \mathrm{~Hz}$. As shown in Figure 11, the MPPT pulse $M C$ is generated once every 128 cycles of $C L K$. For light or thermal energy harvesting, the pulse width of the $M C$ signal is set to 1 cycle (about $8 \mathrm{~ms}$ ) of $C L K$. However, in the case of vibration energy harvesting, it should be set to a longer time. To minimize the ripple of the rectified output when SW1 is open, the PEG's output capacitor $C_{\mathrm{PEG}}$ is set to a value greater than $C_{\mathrm{PVC}}$ or $C_{\mathrm{TEG}}$. Therefore, when the $M C$ signal is high, the time it takes for the output voltage of the PEG to settle to the open-circuit voltage $V_{\mathrm{PEG}, \mathrm{OC}}$ becomes longer. In this design, the pulse width of the $M C$ signal for the PEG is set to 12 cycles of $C L K$.

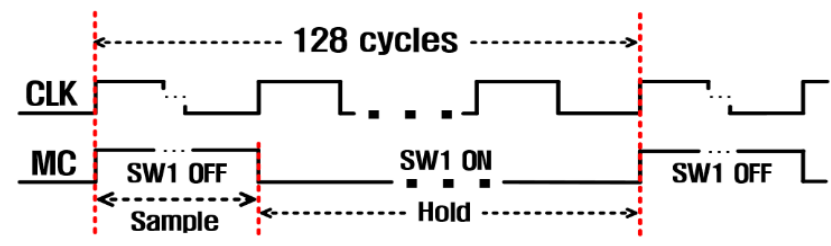

Figure 11. Timing diagram of $C L K$ and $M C$

\subsection{Charge pump (CP)}

To confirm the effectiveness of the proposed MIEH system, the energy harvested from each interface channel is combined using a capacitor-type CP as shown in Figure 12. The CP using dynamic charge transfer switches [43] is advantageous in effectively turning off the switches while minimizing the influence on the threshold voltage of the diode-connected MOSFETs during charge pumping operation. The designed $\mathrm{CP}$ consists of 5 stages, and the stage capacitance $C_{\mathrm{CP}}$ is $20 \mathrm{pF}$.

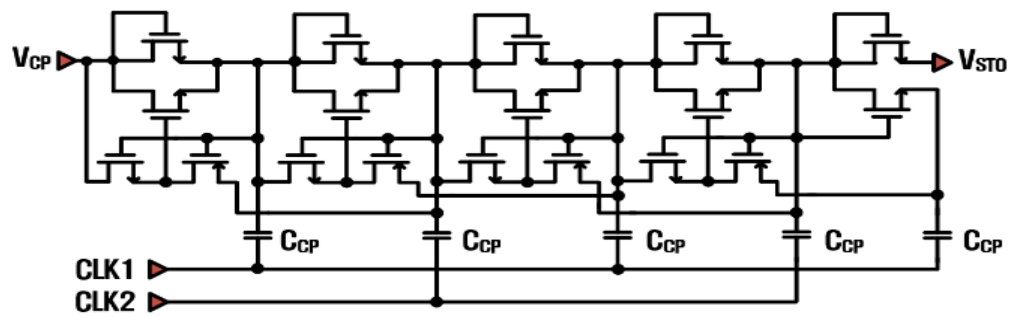

Figure 12. Charge pump schematic

\subsection{Power management unit (PMU)}

Figure 13 shows the block diagram of the PMU designed for transferring the energy stored in $C_{\mathrm{STO}}$ to the load through the BBC control. The designed PMU consists of a power-on reset (POR), a reference generator (BGR), two comparators, a latch, and a PMOS switch (SW3). When the voltage at the storage capacitor, $V_{\mathrm{STO}}$, reaches a predetermined maximum level $V_{\mathrm{STO} \text { MAX }}$, SW3 is turned on, and the energy stored in $C_{\mathrm{STO}}$ is supplied to the load. Normally, the power required by the load is greater than the harvested power, so $V_{\mathrm{STO}}$ decreases. When $V_{\mathrm{STO}}$ decreases to a predetermined minimum level $V_{\mathrm{STO}, \mathrm{MIN}}$, SW3 is turned off, and 
$C_{\text {STO }}$ starts recharging. Therefore, $C_{\text {STO }}$ is repeatedly charged and discharged, and $V_{\text {STO }}$ is band-band controlled between $V_{\text {STO,MAX }}$ and $V_{\text {STO,MIN }}$. This simple power management concept has been implemented in our previous work [35].

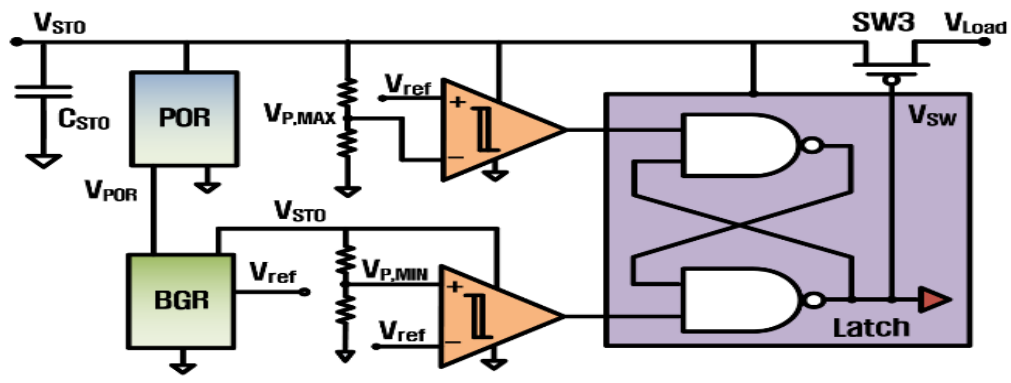

Figure 13. Block diagram of the PMU

\section{EXPERIMENTAL RESULTS}

The proposed MIEH system has been designed and fabricated in a $0.35 \mu \mathrm{m}$ CMOS process and occupies a die area of $3.91 \mathrm{~mm}^{2}$. The chip photograph is shown in Figure 14. The values of the passive elements used in the measurement are as follows: $C_{\mathrm{DD}}=47 \mu \mathrm{F}, C_{\mathrm{STO}}=1 \mathrm{mF}, C_{\mathrm{PVC}}=C_{\mathrm{TEG}}=1 \mathrm{nF}, C_{\mathrm{PEG}}=1 \mu \mathrm{F}$, and $R_{\text {Load }}=10 \mathrm{k} \Omega$. Measurements for PV energy are performed using a Solarbotics solar cell (SCC2422) at a light intensity of $6.5 \mathrm{klux}$, corresponding to the indoor illuminance. In this case, $V_{\mathrm{PVC}, \mathrm{OC}}$ is approximately $2.3 \mathrm{~V}$, and $P_{\mathrm{PVC}, \mathrm{MAX}}$ is $500 \mu \mathrm{W}$. To harvest PE energy, a commercial PZT (QP20W) from Mouser Electronics is mounted on a shaker (Brüel \& Kjær 4810), and the shaker is driven by a power amplifier (Brüel \& Kjær 2718 ) with the command signals from a function generator. In this measurement, the PEG is set to output a $V_{\mathrm{PEG}, \mathrm{OC}}$ of $3 \mathrm{~V}$, and $P_{\mathrm{PEG}, \mathrm{MAX}}$ is $300 \mu \mathrm{W}$. Measurements for TE energy are performed using an equivalent circuit consisting of a $3-\mathrm{V}$ source and a $15-\mathrm{k} \Omega$ series resistor to emulate the TEG described in section 2 . Its $P_{\text {TEG,MAX }}$ is $150 \mu \mathrm{W}$.

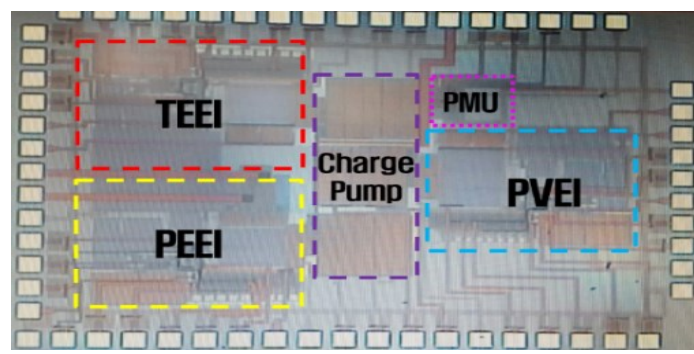

Figure 14. Photograph of the designed chip

Figures 15-17 shows the measured waveforms when only PV energy is harvested. The waveforms measured when the output of the PVEI is connected to a $3-\mathrm{k} \Omega$ resistor instead of the CP are shown in Figure 15. When the $M C_{\mathrm{PVC}}$ signal generated at a period of 1 second is high, $\mathrm{SW} 1_{\mathrm{PVC}}$ is turned off, and the open-circuit voltage $V_{\mathrm{PVC}, \mathrm{OC}}$ of $2.23 \mathrm{~V}$ is generated. While the $M C_{\mathrm{PVC}}$ signal is ' 0 ', the output voltage of the $\mathrm{PVC}$ is maintained between $1.67 \mathrm{~V}$ and $1.4 \mathrm{~V}$, and its average value is $1.54 \mathrm{~V}$, showing a slight difference from the MPP voltage of $1.56 \mathrm{~V}\left(0.7\right.$ times $\left.V_{\mathrm{PVC}, \mathrm{OC}}\right)$. Therefore, it can be confirmed that the PVC operates in the vicinity of the MPP by the MPPT control. The output voltage $V_{\mathrm{CP}, \mathrm{PVC}}$ follows $V_{\mathrm{PVC}}$ while SW2 $2_{\mathrm{PVC}}$ is on, which corresponds to the active time the $\mathrm{CP}$ can operate.

The clock waveforms measured when the output of the PVEI is connected to the CP are shown in Figure 16. It can be seen that while power is supplied from the PVEI to the CP, that is, while $V_{\mathrm{CP}, \mathrm{PVC}}$ is high, the oscillator in the $\mathrm{CP}$ operates to generate clock signals $\left(C L K 1_{\mathrm{PVC}}, C L K 2_{\mathrm{PVC}}\right)$ of $3.67 \mathrm{MHz}$. As can be seen in Figure 17 (a), the voltage $V_{\text {STO }}$ of the storage capacitor is increased by the operation of the CP and then band-band controlled by the PMU. The start-up time it takes to charge $C_{\text {STO }}$ to $V_{\text {STO,MAX }}(2 \mathrm{~V})$ through PV energy harvesting is 66 seconds. The powering time it takes for $V_{\text {STO }}$ to decrease from $V_{\text {STO,MAX }}$ to $V_{\text {STO,MIN }}$ 
$(1.8 \mathrm{~V})$ due to current supply to the load $(10 \mathrm{k} \Omega)$ is 1.1 seconds. The charging time required for $V_{\text {STO }}$ to increase back to $V_{\text {STO,MAX }}$ is 7.5 seconds, so the duty cycle of the power supply to the load is $12.8 \%$. Figure 17 (b) shows the change of $V_{\text {STO }}$ and $V_{\text {Load }}$ waveforms when the light intensity applied to the PVC changes from $7 \mathrm{klux}$ to $1.8 \mathrm{klux}$. The duty cycle is $20 \%$ at $7 \mathrm{klux}$, but decreases to $1.9 \%$ at $1.8 \mathrm{klux}$.

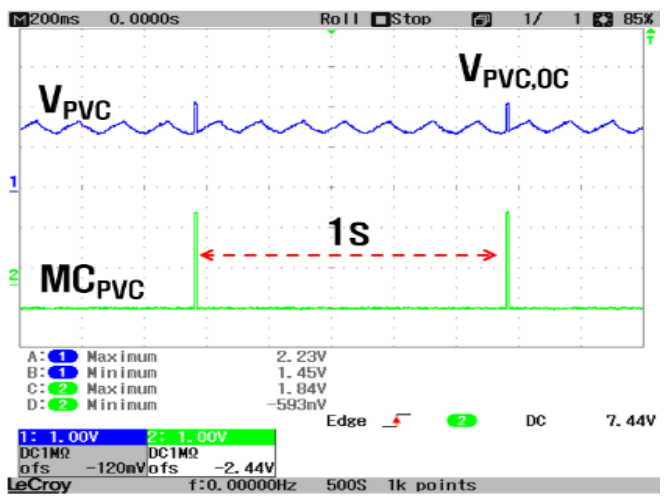

(a)

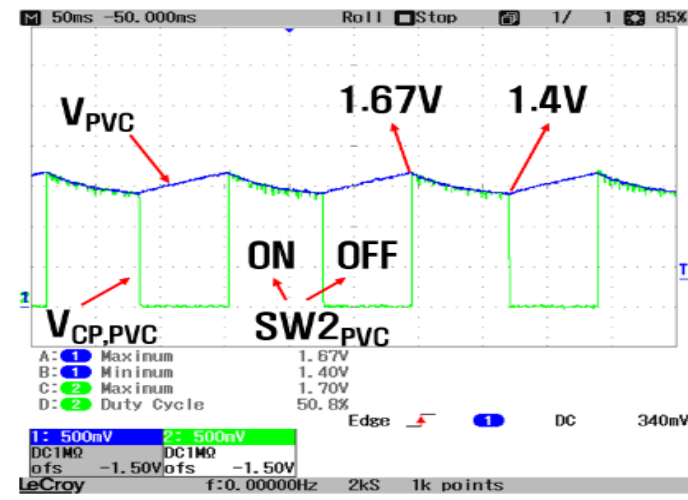

(b)

Figure 15. Waveforms of the PVEI measured at 6.5klux: (a) $V_{\mathrm{PVC}}$ and $M C_{\mathrm{PVC}}$ and (b) $V_{\mathrm{PVC}}$ and $V_{\mathrm{CP}, \mathrm{PVC}}$

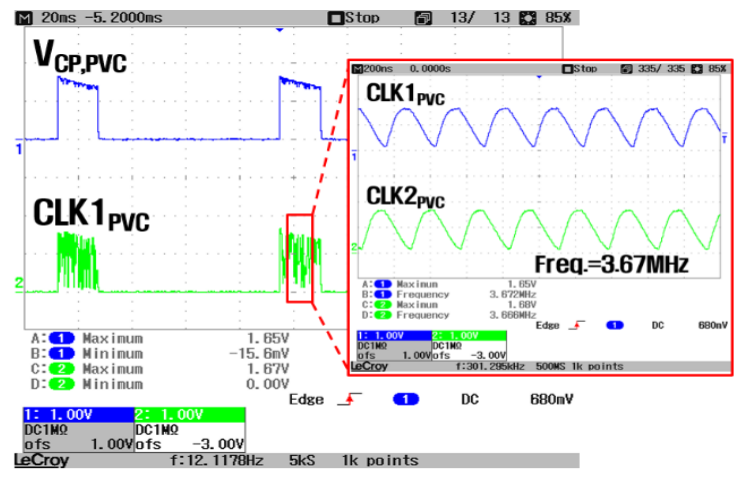

Figure 16. Clock waveforms of the charge pump

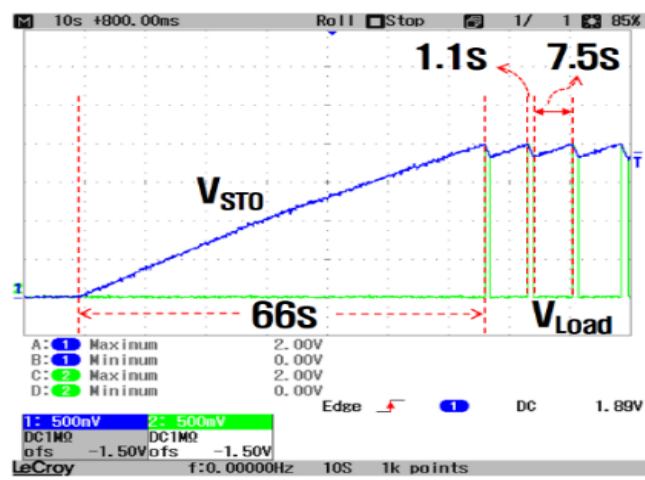

(a)

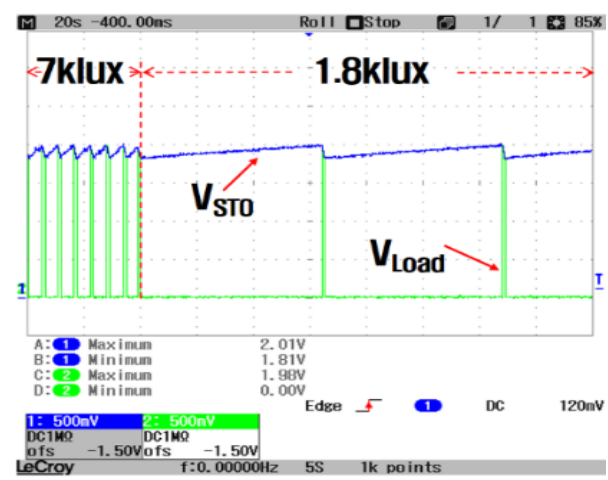

(b)

Figure 17. Waveforms of $V_{\text {STO }}$ and $V_{\text {Load }}$ (a) when only PV energy is harvested and (b) when the light intensity changes from $7 \mathrm{klux}$ to $1.8 \mathrm{klux}$

Figure 18 shows the measured waveforms when the output of the PEEI is connected to a $4.3-\mathrm{k} \Omega$ resistor. The output $V_{\mathrm{PZT}}$ of the PZT, which is an AC-type signal, is converted into a rectified signal $V_{\mathrm{PEG}}$ by the ADC. While the $M C_{\mathrm{PEG}}$ signal is ' 1 ', the ADC's output capacitance becomes $C_{\mathrm{PEG}}$, and $V_{\mathrm{PEG}}$ has a relatively large ripple voltage of up to $180 \mathrm{mV}$. On the other hand, while the $M C$ signal is ' 0 ', since $C_{\mathrm{DD}}$ is added to the output of the ADC, the ripple voltage decreases to a few millivolts. Since $C_{\mathrm{PEG}}$ affects both the 
$V_{\mathrm{PEG}, \mathrm{OC}}$ tracking time and the ripple voltage, it should be optimally selected with an appropriate value. The output voltage of the PEG is band-band controlled between $1.21 \mathrm{~V}$ and $1.68 \mathrm{~V}$ by the MPPT control. Excluding the time when $V_{\mathrm{PEG}, \mathrm{OC}}$ occurs, the average voltage of $V_{\mathrm{PEG}}$ is $1.45 \mathrm{~V}$, which is slightly smaller than the MPP voltage $\left(V_{\mathrm{PEG}, \mathrm{MPP}}=1.5 \mathrm{~V}\right)$, but it can be seen that the PE energy is being harvested near the MPP.

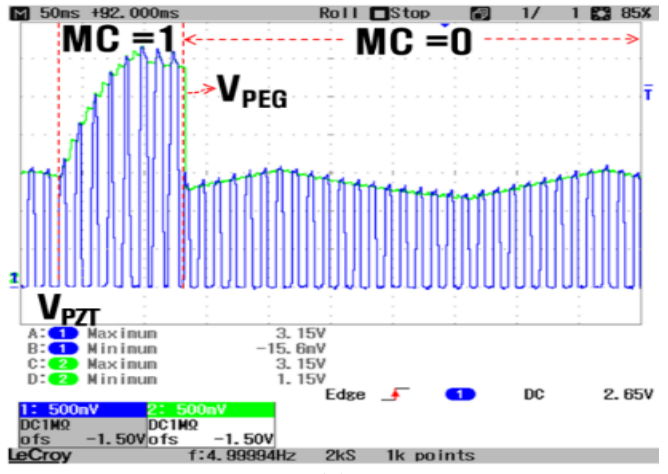

(a)

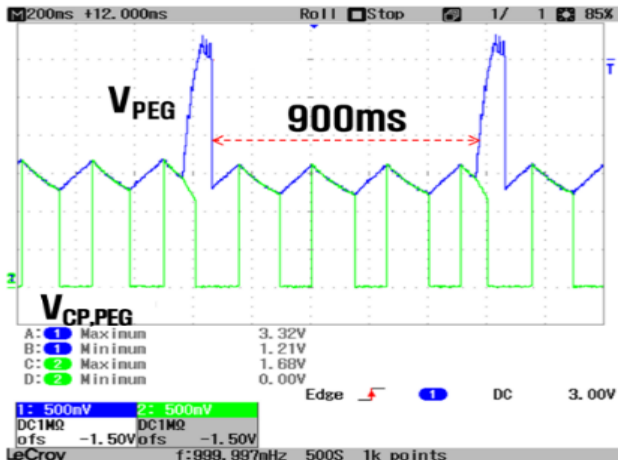

(b)

Figure 18. Waveforms of the PEEI: (a) $V_{\mathrm{PZT}}$ and $V_{\mathrm{PEG}}$ and (b) $V_{\mathrm{PEG}}$ and $V_{\mathrm{CP}, \mathrm{PEG}}$

When the output of the PEEI is connected to the CP, the operating characteristics of the CP and PMU are similar to those of PVEI shown in Figure 16 and 17. The measured characteristics of the TEEI, a thermal energy interface channel, are also similar to those of the PVEI. The measured power efficiencies of the interface channels in the designed EHB are shown in Figure 19. The peak power efficiency of the PVEI, PEEI, and TEEI is $95.2 \%, 92.5 \%$, and $95.5 \%$, respectively. Compared to the other two cases, the overall efficiency of the PEEI is inferior because the pulse width of the $M C$ signal for sampling the open-circuit voltage is relatively long, reducing the energy harvesting time. In addition, the use of an ADC causes an additional reduction in power efficiency.

Figure 20(a) shows the comparison of $V_{\text {STO }}$ waveforms for single-input energy harvesting, i.e., when PV, PE, and TE energy are harvested separately. In the case of PV energy harvesting, the start-up time is the fastest, followed by PE energy harvesting. The duty cycle is also the largest for PV energy harvesting. This is because the maximum available power of the input devices used in this experiment is the largest in PVC at $500 \mu \mathrm{W}$, followed by PEG at $300 \mu \mathrm{W}$, and TEG at $150 \mu \mathrm{W}$. Figure $20(\mathrm{~b})$ shows the results of energy harvesting for single input, dual input, and triple input cases. Their detailed characteristics are summarized in Table 2. As expected, as the number of inputs increases, the start-up time decreases, and the duty cycle increases. These results confirm the functionality of the proposed MIEH system.

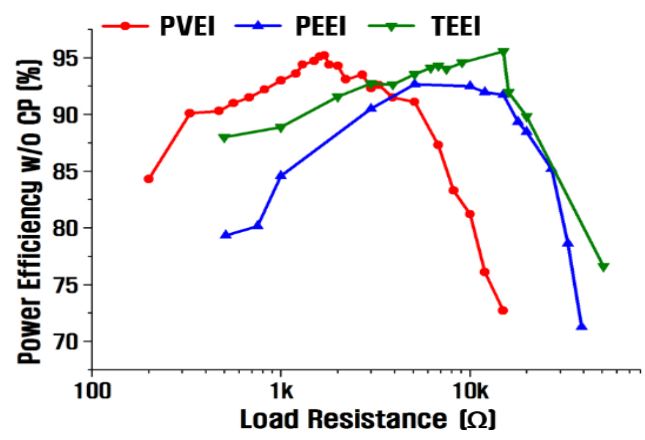

Figure 19. Power efficiency graphs of the EHB interfaces

Table 2. $V_{\text {STO }}$ characteristics for multi-input energy harvesting

\begin{tabular}{ccccc}
\hline & Start-up time (s) & Powering time (s) & Charging time (s) & Duty cycle (\%) \\
\hline PVC & 66 & 1.1 & 7.5 & 12.8 \\
PVC+TEG & 49 & 1.2 & 3.9 & 23.5 \\
PVC+PEG+TEG & 34 & 1.5 & 2.6 & 36.6 \\
\hline
\end{tabular}




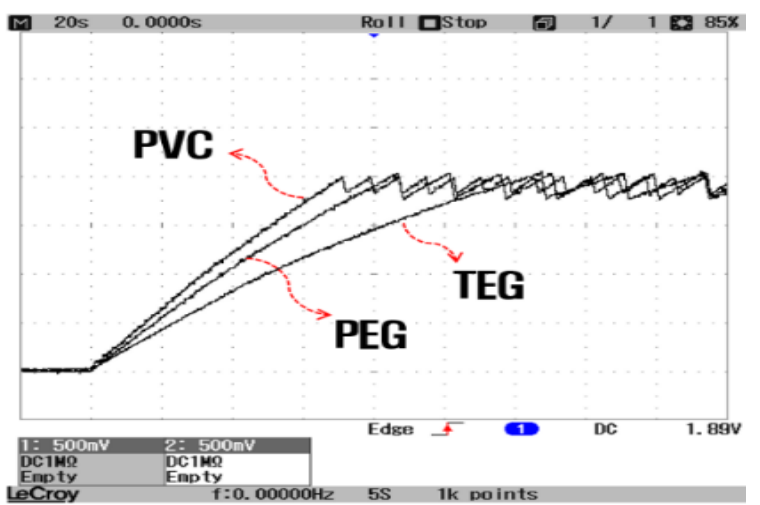

(a)

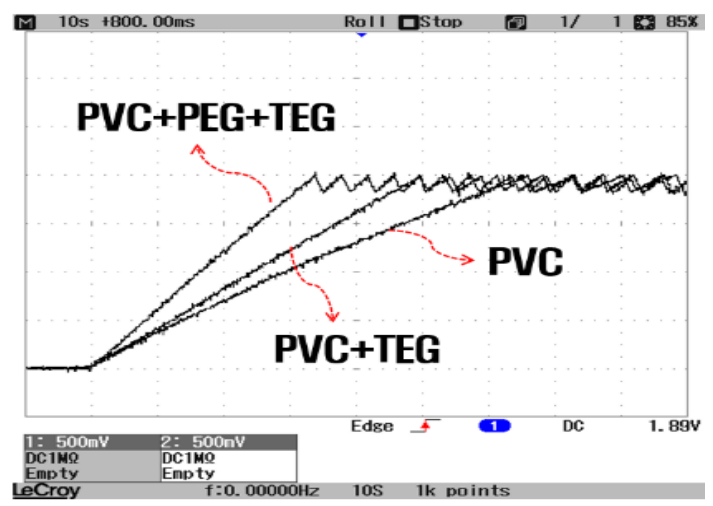

(b)

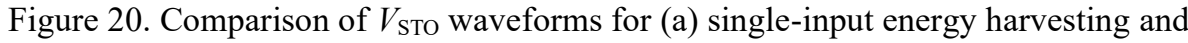
(b) multi-input energy harvesting

\section{CONCLUSION}

This paper presented a MIEH system where an EHB and a PMB are independent of each other. The EHB has been implemented using three interfaces: a PVEI, a PEEI, and a TEEI. Each interface has been optimized independently to extract maximum available power from its energy source using the proposed simple MPPT controller based on the FOCV method. The measured peak power efficiencies of the PVEI, PEEI, and TEEI are $95.2 \%, 92.5 \%$, and $95.5 \%$, respectively. The functionality and effectiveness of the proposed MIEH system have also been experimentally verified by implementing the EHB with a PMB consisting of simple charge pump circuits and a power management unit. In the proposed system, the number of inputs can be easily expanded due to its high modularity. In addition, since the EHB and PMB are independent, it is possible to add or remove energy sources without modifying the PMB.

\section{ACKNOWLEDGEMENTS}

This work was supported by Incheon National University Research Grant in 2018 and was partially supported by IDEC.

\section{REFERENCES}

[1] T. Ruan, Z. J. Chew and M. Zhu, "Energy-Aware Approaches for Energy Harvesting Powered Wireless Sensor Nodes,” IEEE Sensors Journal, vol. 17, no. 7, pp. 2165-2173, Apr. 2017, doi: 10.1109/JSEN.2017.2665680.

[2] Y. Zhang, et al., "A Batteryless $19 \mu \mathrm{W}$ MICS/ISM-Band Energy Harvesting Body Sensor Node SoC for ExG Applications," IEEE J. Solid-State Circuits, vol. 48, no. 1, pp. 199-213, Jan. 2013, doi: 10.1109/JSSC.2012.2221217.

[3] D. A. Hammood, et al., "IoT for health-based system: analog network coding with energy harvesting," Indonesian Journal of Electrical Engineering and Computer Science, vol. 20, no. 2, pp. 822-829, Nov. 2020, doi: 10.11591/ijeecs.v20.i2.pp822-829.

[4] S. Touairi and M. Mabrouki, "Vibration harvesting integrated into vehicle suspension and bodywork," Indonesian Journal of Electrical Engineering and Computer Science, vol. 23, no. 1, pp. 188-196, July 2021, doi: 10.11591/ijeecs.v23.i1.pp188-196.

[5] H. Kim, et al., "A $10.6 \mathrm{~mm}^{3}$ fully-integrated, wireless sensor node with $8 \mathrm{GHz}$ UWB transmitter," in Proc. Symp. on VLSI Circuits, Kyoto, Japan, pp. C202-C203, 2015, doi: 10.1109/VLSIC.2015.7231258.

[6] A. L. Mansano, Y. Li, S. Bagga, and W. A. Serdijn, "An Autonomous Wireless Sensor Node With Asynchronous ECG Monitoring in $0.18 \mu \mathrm{m}$ CMOS," IEEE Trans. on Biomedical Circuits and Systems, vol. 10, no. 3, pp. 602-611, June 2016, doi: 10.1109/TBCAS.2015.2495272.

[7] P. D. Mitcheson, "Energy harvesting for human wearable and implantable bio-sensors," in Proc. IEEE Eng. Med. Biol. Soc. Conf., Jan. 2010, pp. 3432-3436, doi: 10.1109/IEMBS.2010.5627952.

[8] R. Bolt, M. Magno, T. Burger, A. Romani, and L. Benini, "Kinetic AC/DC converter for electromagnetic energy harvesting in autonomous wearable devices," IEEE Trans. on Circuits and Systems II, vol. 64, no. 12, pp. 1422-1426, Dec. 2017, doi: 10.1109/TCSII.2017.2768391.

[9] M. J. Weber, Y. Yoshihara, A. Sawaby, J. Charthad, T. C. Chang, and A. Arbabian, "A miniaturized singletransducer implantable pressure sensor with time-multiplexed ultrasonic data and power links," IEEE J. Solid-State Circuits, vol. 53, no. 4, pp. 1089-1101, Apr. 2018, doi: 10.1109/JSSC.2017.2782086. 
[10] J. Colomer-Farrarons, P. Miribel-Catala, A. Saiz-Vela, M. Puig-Vidal, and J. Samitier, "Power-Conditioning Circuitry for a Self-Powered System Based on Micro PZT Generators in a 0.13- $\mu \mathrm{m}$ Low-Voltage Low-Power Technology," IEEE Trans. on Industrial Electronics, vol. 55, no. 9, pp. 3249-3257, Sept. 2008, doi: 10.1109/TIE.2008.927973.

[11] C. Lu, C. Tsui, and W. Ki, "Vibration Energy Scavenging System With Maximum Power Tracking for Micropower Applications," IEEE Trans. on VLSI Systems, vol. 19, no. 11, pp. 2109-2119, 2011, doi: 10.1109/TVLSI.2010.2069574.

[12] V. Boscaino, V. Ferraro, R. Miceli, G. Capponi, and R. Proietto, "A multi-input, single-inductor power system for multisource energy harvesting," in Proc. Int. Conf. on Renewable Energy Research and Applications, Madrid, Spain, 2013, pp. 252-257, doi: 10.1109/ICRERA.2013.6749761.

[13] G. Yu, K. W. R. Chew, Z. C. Sun, H. Tang, and L. Siek, "A $400 \mathrm{nW}$ single-inductor dual-input-tri-output DC-DC buck-boost converter with maximum power point tracking for indoor photovoltaic energy harvesting," IEEE J. Solid-State Circuits, vol. 50, no. 11, pp. 2758-2772, Nov. 2015, doi: 10.1109/JSSC.2015.2476379.

[14] X. Wang et al., "Multi-Input SECE Based on Buck Structure for Piezoelectric Energy Harvesting," IEEE Trans. on Power Electronics, vol. 36, no. 4, pp. 3638-3642, Apr. 2021, doi: 10.1109/TPEL.2020.3022424.

[15] M. Ferrari, V. Ferrari, M. Guizzetti, D. Marioli, and A. Taroni, "Piezoelectric multifrequency energy converter for power harvesting in autonomous microsystems," Sens. Actuators A, Phys., vol. 142, no. 1, pp. 329-335, Mar. 2008, doi: $10.1016 /$ j.sna.2007.07.004.

[16] N. G. Elvin and A. A. Elvin, "Vibrational Energy Harvesting From Human Gait," IEEE/ASME Trans. on Mechatronics, vol. 18, no. 2, pp. 637-644, Apr. 2013, doi: 10.1109/TMECH.2011.2181954

[17] S. C. Chandrarathna and J.-W. Lee, "A dual-stage boost converter using two-dimensional adaptive input-sampling MPPT for thermoelectric energy harvesting," IEEE Trans. on Circuits and Systems I, vol. 66, no. 12, pp. 4888-4900, Dec. 2019, doi: 10.1109/TCSI.2019.2935221.

[18] C. Park and P. H. Chou, "AmbiMax: Autonomous Energy Harvesting Platform for Multi-Supply Wireless Sensor Nodes," in Proc. 3rd Annu. IEEE Commun. Society on Sensor and Ad Hoc Commun. and Networks, Reston, VA, USA, pp. 168-177, 2006, doi: 10.1109/SAHCN.2006.288421.

[19] J. Colomer-Farrarons, P. Miribel-Catala, A. Saiz-Vela, and J. Samitier, "A Multiharvested Self-Powered System in a Low-Voltage Low-Power Technology," IEEE Trans. on Industrial Electronics, vol. 58, no. 9, pp. 4250-4263, Sept. 2011, doi: 10.1109/TIE.2010.2095395.

[20] H. Li, G. Zhang, R. Ma, and Z. You, "Design and Experimental Evaluation on an Advanced Multisource Energy Harvesting System for Wireless Sensor Nodes," The Scientific World Journal, 2014, doi: 10.1155/2014/671280.

[21] C. Shi, B. Miller, K. Mayaram, and T. Fiez, "A Multiple-Input Boost Converter for Low-Power Energy Harvesting," IEEE Trans. on Circuits and Systems II, vol. 58, no. 12, pp. 827-831, Dec. 2011, doi: 10.1109/TCSII.2011.2173974.

[22] S. Bandyopadhyay and A. P. Chandrakasan, "Platform Architecture for Solar, Thermal, and Vibration Energy Combining With MPPT and Single Inductor," IEEE J. Solid-State Circuits, vol. 47, no. 9, pp. 2199-2215, Sept. 2012, doi: $10.1109 /$ JSSC.2012.2197239.

[23] C. Chang and T. Lee, "A compact multi-input thermoelectric energy harvesting system with 58.5\% power conversion efficiency and 32.4-mW output power capability," in Proc. Int. Symp. on Integrated Circuits, Singapore, 2014, pp. 1-4, doi: 10.1109/ISICIR.2014.7029491.

[24] M. Dini, A. Romani, M. Filippi, V. Bottarel, G. Ricotti, and M. Tartagni, "A Nanocurrent Power Management IC for Multiple Heterogeneous Energy Harvesting Sources," IEEE Trans. on Power Electronics, vol. 30, no. 10, pp. 5665-5680, Oct. 2015, doi: 10.1109/TPEL.2014.2379622.

[25] S. S. Amin and P. P. Mercier, "MISIMO: A multi-input single-inductor multi-output energy harvesting platform in 28-nm FDSOI for powering net-zero-energy systems," IEEE J. Solid-State Circuits, vol. 53, no. 12, pp. 3407-3419, Dec. 2018, doi: 10.1109/JSSC.2018.2865467.

[26] S. C. Chandrarathna and J.-W. Lee, "A $580 \mathrm{nW}$ Dual-Input Energy Harvester IC Using Multi-Task MPPT and a Current Boost Converter for Heterogeneous Source Combining," IEEE Trans. on Circuits and Systems I, vol. 67, no. 12, pp. 5650-5663, Dec. 2020, doi: 10.1109/TCSI.2020.3015989.

[27] J.-G. Parada-Salado, L. F. Gaona-Cárdenas, M. A. Rodríguez-Licea, and F. J. Perez-Pinal, "Harvesting in electric vehicles: Combining multiple power tracking and fuel-cells," International Journal of Electrical and Computer Engineering, vol. 10, no. 5, pp. 5058-5073, Oct. 2020, doi: 10.11591/ijece.v10i5.pp5058-5073.

[28] J. H. Yap and Y. C. Wong, "A $30 \mathrm{mV}$ input battery-less power management system," Bulletin of Electrical Engineering and Informatics, vol. 8, no. 4, pp. 1169-1179, Dec. 2019, doi: 10.11591/eei.v8i4.1614.

[29] M. S. Tamrin and M. R. Ahmad, "Simulation of adaptive power management circuit for hybrid energy harvester and real-time sensing application," International Journal of Power Electronics and Drive System, vol. 11, no. 2, pp. 658-666, Jun. 2020, doi: 10.11591/ijpeds.v11.i2.pp658-666.

[30] H. Lhermet, C. Condemine, M. Plissonnier, R. Salot, P. Audebert, and M. Rosset, "Efficient Power Management Circuit: From Thermal Energy Harvesting to Above-IC Microbattery Energy Storage," IEEE J. Solid-State Circuits, vol. 43, no. 1, pp. 246-255, Jan. 2008, doi: 10.1109/JSSC.2007.914725.

[31] N. J. Guilar, R. Amirtharajah, P. J. Hurst, and S. H. Lewis, "An energy-aware multiple-input power supply with charge recovery for energy harvesting applications," in Proc. IEEE Int. Solid-State Circuits Conf. - Dig. of Tech. Papers, San Francisco, CA, USA, 2009, pp. 298-299, doi: 10.1109/ISSCC.2009.4977426.

[32] J. Kim and C. Kim, "A DC-DC Boost Converter With Variation-Tolerant MPPT Technique and Efficient ZCS Circuit for Thermoelectric Energy Harvesting Applications," IEEE Trans. on Power Electronics, vol. 28, no. 8, pp. 3827-3833, Aug. 2013, doi: 10.1109/TPEL.2012.2231098. 
[33] D. Dondi, et al., "Modeling and Optimization of a Solar Energy Harvester System for Self-Powered Wireless Sensor Networks," IEEE Trans. on Industrial Electronics, vol. 55, no. 7, pp. 2759-2766, July 2008, doi: 10.1109/TIE.2008.924449.

[34] C. Lu, V. Raghunathan, and K. Roy, "Maximum power point considerations in micro-scale solar energy harvesting systems," in Proc. IEEE Int. Symp. on Circuits and .Systems, Paris, France, pp. 273-276, 2010, doi: 10.1109/ISCAS.2010.5537888.

[35] E.-J. Yoon and C.-G. Yu, "Power management circuits for self-powered systems based on micro-scale solar energy harvesting," International Journal of Electronics, vol. 103, no. 3, pp. 516-529, Mar. 2016, doi: 10.1080/00207217.2015.1036802.

[36] SCC2422, Solarbotics. Available: http://www.solarbotics.com

[37] QP20W, Mouser Electronics. Available: http://www.mouser.com

[38] V. Leonov, P. Fiorini, S. Sedky, T. Torfs, and C. Van Hoof, "Thermoelectric MEMS generators as a power supply for a body area network," in Proc. The 13th Int. Conf. on Solid-State Sensors, Actuators and Microsystems, Seoul, Korea, 2005, pp. 291-294.

[39] Thermo Life ${ }^{\mathrm{TM}}$, Thermo Life Energy Corp. Available: http://www.poweredbythermolife.com

[40] C. Sauer, M. Stanacevic, G. Cauwenberghs, and N. Thakor, "Power harvesting and telemetry in CMOS for implanted devices," IEEE Trans. on Circuits and Systems I, vol. 52, no. 12, pp. 2605-2613, Dec. 2005, doi: 10.1109/TCSI.2005.858183.

[41] E.-J. Yoon and C.-G. Yu, "Self-powered High-performance Full-wave Rectifier with a Vibration Detection Function for Energy Harvesting Applications," Journal of Semiconductor Technology and Science, vol. 17, no. 6, pp. 815-824, Dec. 2017, doi: 10.5573/JSTS.2017.17.6.815.

[42] E.-J. Yoon, J.-T. Park, and C.-G. Yu, "Thermal energy harvesting circuit with maximum power point tracking control for self-powered sensor node applications," Frontiers of Information Technology \& Electronic Engineering, vol. 19, no. 2, pp. 285-296, Apr. 2018, doi: 10.1631/FITEE.1601181.

[43] J.-T. Wu and K.-L. Chang, "MOS charge pumps for low-voltage operation," IEEE J. Solid-State Circuits, vol. 33, no. 4, pp. 592-597, Apr. 1998, doi: 10.1109/4.663564.

\section{BIOGRAPHIES OF AUTHORS}

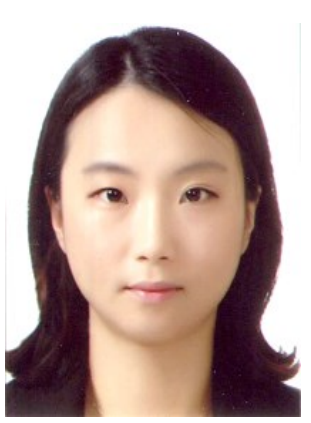

Eun Jeong Yun received the B.S., M.S., and Ph.D. degrees in Electronics Engineering from Incheon National University, Incheon, Korea, in 2011, 2013, and 2017, respectively. She is currently a research specialist at Silicon Works Co., Ltd. Her research interests include microscale energy harvesting system design and analog/mixed-mode IC design.

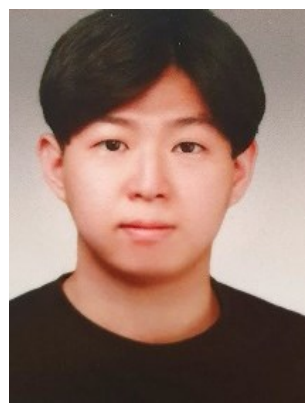

Hyun Joong Kim received the B.S. degree in Electronics Engineering from Incheon National University, Incheon, Korea, in 2020. He is currently pursuing the M.S. degree. His research interests are micro-scale energy harvesting system design and analog/mixed-mode IC design.

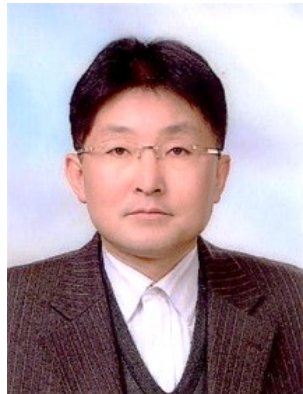

Chong Gun Yu received the B.S. and M.S. degrees in Electronics Engineering from Yonsei University, Seoul, Korea in 1985 and 1987, respectively. He was a graduate student at Texas A\&M University, College Station, TX from 1989 to 1991. He received the Ph.D. degree in Electrical and Computer Engineering from Iowa State University, Ames, IA in 1993. He joined the Department of Electronics Engineering, Incheon National University, Incheon, Korea in 1994, and currently serves as Professor. His research interests are micro-scale energy harvesting system design and analog/mixed-mode IC design. 